\title{
Una mirada antropológica a la estética y personificación de los objetos. El caso del berimbau en la capoeira angola en Brasil
}

\author{
Sergio González Varela
}

Este artículo presenta un análisis de los objetos estéticos desde una perspectiva antropológica, basado en las reflexiones teóricas desarrolladas principalmente por Alfred Gell y Marilyn Strathern. Posicionado como una alternativa a algunos de los planteamientos provenientes de la semiótica estructural, el argumento central se basa en la capacidad relacional que los objetos tienen para transformarse en personas o en sujetos dentro de un contexto cultural. Este potencial de personificación se sustenta etnográficamente en la descripción de los usos, representaciones y percepciones que se hacen del berimbau, un instrumento musical dentro del ritual de la capoeira angola en Brasil.

PALABRAS CLAVE: objetos, estética, personificación, capoeira, música

\section{An Anthropological Approach to the Aesthetics and Personification of Objects: The Case of the Berimbau in Capoeira Angola in Brazil}

This article presents an analysis of aesthetic objects from an anthropological perspective based on the theoretical reflections developed mainly by Alfred Gell and Marilyn Strathern. Positioned as an alternative of some ideas coming from structural semiotics, the central argument is based on the relational capacity of the objects in order to become and transform themselves into persons or subjects within a cultural context. This personification potential is sustained ethnographically by describing the uses, representations and perceptions made about the berimbau, a music instrument of the ritual of capoeira Angola in Brazil.

KEYWORDS: objects, aesthetics, personification, capoeira, music

Sergio González Varela: Coordinación de Ciencias Sociales y Humanidades, Universidad Autónoma de San Luis Potosí,

San Luis Potosí, México

sergio.gonzalez@uaslp.mx

Desacatos, núm. 40, septiembre-diciembre 2012, pp. 127-140

Recepción: 14 de enero de 2011 / Aceptación: 15 de mayo de 2012 


\section{INTRODUCCIÓN}

$\mathrm{E}$ 1 análisis de la estética de los objetos materiales desde una perspectiva antropológica se presenta como un desafío teórico que nos obliga no sólo a repensar los mecanismos de relación entre lo material y lo social, también nos invita a reflexionar sobre la influencia que tienen dichos objetos en la creación de relaciones sociales entre individuos. Por tanto, el presente artículo se define como un experimento analítico en el que se evalúa el impacto estético y relacional que ha generado la proliferación de artefactos en la conformación de la cultura, teniendo como evidencia etnográfica algunos aspectos referentes a la música dentro del ritual de la capoeira angola en Brasil.

La idea de relacionar lo social con la proliferación estética de lo material, aquellas "cosas" creadas localmente, no es algo del todo nuevo, aparece en diversos desarrollos antropológicos dedicados al arte, entre los que cabe resaltar como el planteamiento más claro y delimitado - quizá- el de Alfred Gell (1998), quien en su libro Art and Agency plantea la posibilidad de una antropología de lo visual. Gell hace una distinción importante entre los objetivos primordiales de la historia del arte, la teoría del arte y la antropología del arte. En las dos primeras se busca el análisis de la recepción visual y emotiva del objeto de contemplación artística y su evaluación estética. En la última, Gell es enfático al mencionar que la antropología del arte tiene que enfocarse sobre todo en el contexto social de producción, circulación y recepción del objeto artístico (Gell, 1998: 3). De acuerdo con la concepción del antropólogo británico:

La antropología del arte no puede concebirse como el estudio de los principios estéticos de ésta o aquella cultura, sino en el de la movilización de los principios estéticos (o algo parecido) en el curso de la interacción social (Gell, 1998: 4).

Por tanto, la tarea en cuestión radica en invertir algunos de los estatutos clásicos de la teoría del arte.
En vez de aplicar cierta teoría estética occidental a los objetos de arte de los otros, se propone aplicar algunos puntos centrales de la teoría antropológica al estudio del arte de la alteridad (Gell, 1998: 4). La inversión que apunta Gell es compartida en este artículo, que parte del supuesto de que las producciones materiales, sean imágenes - históricas, pictóricas, fotográficas, religiosas, artísticas o ilustrativas - u objetos de contemplación estética - esculturas, edificios, instrumentos rituales, musicales, ceremoniales, etc.-, no pueden ser desarraigadas del contexto en el cual fueron o son producidas, exhibidas y compartidas. Las imágenes no pueden ser analizadas sin remitir al entorno del que proceden o a los elementos culturales que intervinieron en su creación.

No obstante el principio metodológico propuesto por Gell, es importante señalar que la relación entre objeto y contexto opera también de un modo recursivo: es decir, tanto los objetos materiales cobran mayor sentido al ser puestos en contexto como el contexto cultural resulta enriquecido con los elementos que aparecen en los propios objetos. Ahora bien, explicar la estrecha vinculación entre objeto y contexto puede suscitar algunas objeciones y reticencias, en particular desde el ámbito de la semiótica. La siguiente sección abordará algunos de los puntos más importantes de digresión entre el tipo de antropología planteada en el artículo y la posición tradicional de la semiótica estructural, para después proponer una alternativa al estudio cultural de los objetos estéticos.

\section{LOS LÍMITES DEL “OBJETO EN SÍ” FORMULADOS POR LA SEMIÓTICA ESTRUCTURAL}

Antes que nada quisiera mencionar que la palabra "semiótica" usada en este texto se refiere principalmente a los planteamientos estructuralistas franceses y a algunos provenientes de la escuela formalista rusa. En ningún caso se extrapola a los desarrollos 
de la semiótica pierciana, que se diferencia considerablemente en método, lineamientos y fundamentos filosóficos de la semiótica estructural. Desde los planteamientos iniciales de la semiótica francesa - sobre todo en la obra temprana de Roland Barthes, quien define la semiótica o semiología como "una ciencia de las formas, puesto que estudia las significaciones independientemente de su contenido" (Barthes, 1999: 202) - pueden percibirse algunos de los ejes centrales de la discusión sobre el objeto de estudio de dicha disciplina y la manera de estudiarlos.

El énfasis en la dilucidación de las formas que otorgan sentido al objeto semiológico, sea mito, imagen o texto, se sustenta en la diferenciación clásica que Saussure hace entre significante y significado como dos caras de la misma moneda, elementos indispensables en la constitución de un signo (Saussure, 1996: 99-106). La llamada arbitrariedad del signo, por tanto, posibilita la proliferación de objetos capaces de irradiar sentido por su propia naturaleza de convertirse en evocaciones de algo. En el caso de Barthes, textos e imágenes pueden ser susceptibles de convertirse en signos por su potencialidad de significar o de ser significados, en síntesis, por su cualidad de posicionarse como lenguajes-objetos (Barthes, 1999: 206). Dicho posicionamiento hace posible que los objetos e imágenes adquieran por definición un estatuto de desciframiento, en el sentido de que es posible "extraer" algo de ellos que visiblemente, a nivel perceptual, no se puede apreciar en primera instancia.

El carácter metafórico de equiparación entre objeto/imagen y lenguaje se encuentra en la base misma de la semiótica francesa. Esto permite extender, a veces de manera un poco desmedida, la afirmación de que los objetos/imágenes constituyen en sí mismos formas significativas. Esta idea de contención parece perdurar en cierto modo en análisis subsecuentes de Barthes y en los planteamientos posteriores de la semiótica greimasiana. La amplitud de temas que abarca la producción intelectual de Barthes hace difícil su sistematización y sería injusto resumir sus aportes a algunos breves pasajes de su obra temprana. No obstante, quisiera remitirme a algunas de sus reflexiones más perdurables a partir de las cuales se instituirá el proyecto de la semiótica francesa como la ciencia del sentido de los "objetos en sí. En Crítica y verdad, Barthes deja de manifiesto el nuevo rumbo a seguir para la crítica literaria, cuando de cierta manera declara la "muerte del autor" en los estudios literarios. La convicción de la semiótica de convertirse en una ciencia objetiva la obliga a desistir de referencias externas al texto en sí (Barthes, 1985). Esta cualidad de autocontención significativa hace posible que Barthes equipare el texto literario con el mito: “ ¿Cómo la ciencia puede hablar de un autor? La ciencia de la literatura no puede sino emparentar la obra literaria, aunque esté firmada, al mito, que no lo está" (Barthes, 1985: 61). Más adelante establece la relevancia propia del autor, su contexto y su obra en el análisis semiótico de la literatura:

Habrá pues que aceptar el distribuir los objetos de la ciencia literaria. El autor, la obra, no son más que el punto de partida de un análisis cuyo horizonte es un lenguaje: no puede haber una ciencia de Dante, de Shakespeare o de Racine, sino únicamente una ciencia del discurso (Barthes, 1985: 63).

La "muerte del autor", vista como el sacrificio indispensable para el análisis seguro de los objetos, purifica el método por medio del cual la semiótica captará o hará inteligible su sentido o significado "real". En el caso de la semiótica greimasiana, esto queda patente en las bases del método de análisis del discurso. Greimas es claro al posicionar la búsqueda del sentido del texto literario como un estudio de las formas y no de las motivaciones. Su preocupación no consiste en saber quién hizo el texto, por qué dice el texto lo que dice, cuál es el contenido del texto, sino cómo dice el texto lo que dice (Greimas y Courtès, 1991). Esta inmanencia del texto será una de las condiciones intrínsecas de la semiótica greimasiana. La idea de totalidad que el 
texto despliega en sí mismo posibilita una especie de arquitectura del sentido en la que el texto aparece como un dispositivo estructurado de reglas y relaciones que diferencia niveles tanto superficiales como profundos. La arquitectura del sentido puede ser captada por medio de elementos o herramientas metodológicas que forman el núcleo de la complejidad de la teoría del análisis de los textos de Greimas. Ante la imposibilidad de ahondar en la terminología greimasiana y su forma de análisis textual por falta de espacio, sólo me limito a señalar que el ejemplo más claro de ella se encuentra en el estudio que Greimas hace de un cuento de Maupassant (Greimas, 1983) donde se pone en evidencia la efectividad del análisis semiótico-estructural.

A pesar de la rigurosidad analítica de Greimas y su abundante producción académica, la idea de totalidad en sí que encierra al objeto estético y que se presenta como condición intrínseca para su estudio no deja de mostrar ciertas inconsistencias. Por un lado, los elementos externos a su "autosuficiencia" y las imágenes estéticas hacia nuevas posibilidades, donde el objetivo primordial consiste en una resemantización de la vida (Greimas, 1997: 87). Esta renovación de los objetivos de la teoría semiótica coloca a Greimas en un nivel de discusión filosófica que trasciende los límites que él mismo se había impuesto y su pensamiento en una situación más flexible y más sofisticada al vincular la experiencia de semiosis con la experiencia estética. Es al mismo tiempo un esfuerzo por incluir aspectos externos al texto como vitales en la propia creación del sentido, lo que Paul Ricoeur (2000) calificaría como un paso de un modelo explicativo hacia un modelo de comprensión. En dicho movimiento se puede percibir un vínculo quizá más estrecho con la hermenéutica y con el problema que suscita la fenomenología de la interpretación comunicativa y el diálogo entre texto y lector, o entre objeto y sujeto.

En la siguiente sección veremos que la antropología social puede beneficiarse por ese cambio y apertura de la reflexión semiótica que otorga al objeto estético un carácter de eterna imperfección o de sentido incompleto y de diálogo. El estatus ontológico del objeto o de la imagen depende irremediablemente de su relación con un contexto que es maleable, cambiante y que filtra incesantemente las vanas acotaciones hechas por las ideas de autosuficiencia del objeto en sí.

\section{LA PERSONIFICACIÓN DE LOS OBJETOS}

El reconocimiento del sujeto como parte activa en el proceso de semiosis abre el objeto estético hacia una dimensión en la que se vinculan de manera estrecha la antropología y la comunicación significativa. El objeto antes purificado entra en un nivel donde su estatus ontológico dependerá del grado de interacción que tenga en un nivel tanto individual como social y simbólico. De esta manera, su carácter se definirá por el grado de interrelación que pueda crear. Esto no implica que su condición sea dada por su necesidad funcional o instrumental dentro de 
una cultura. Como ha mencionado Jean Baudrillard, se requiere ir más allá de su funcionalidad y acercarse a la forma en que los sujetos crean relaciones con los objetos y se ven afectados al mismo tiempo por ellos en un sentido más profundo (Baudrillard, 1997: 2). Esto nos remite a algunos puntos desarrollados por Gell, en los que conceptos como "agency" —agencia, influencia o "agentividad"-, "intención", "causa" y "resultado" hacen de los objetos estéticos elementos activos en la transformación e invención de la cultura (Gell, 1998: 6). Esta revaloración del objeto estético revierte y trastoca las ideas de una semiótica capaz de purificarlo y aislarlo en su sentido más primordial. No hay semiótica del texto sin lector, podríamos decir. No existen formas estéticas en sí sin un sujeto que las identifique como tales.

La noción de "objeto estético" de la que habla Gell no se remite a cosas inanimadas, incluye cosas, animales y personas. Una persona puede convertirse en un objeto de arte y, recursivamente, un objeto de arte puede tornarse en una persona. La noción de "artefacto" pudiera ser un mejor sustituto para encontrar una definición menos elusiva y engañosa del lenguaje para hablar de "cosas", "objetos" o "sustancias". Como ha precisado Marilyn Strathern (1999), por lo menos en el idioma inglés es indispensable hacer la distinción entre "objects" - objetos- $\mathrm{y}$ "things" - cosas-, sobre todo en contextos culturales en los que nuestras concepciones de la proliferación de lo visible no son del todo compartidas. En el caso de los hagen de Nueva Guinea, Strathern comenta que es imprescindible evitar caer en conclusiones apresuradas y pensar que individuos, conchas y perros, por así decirlo, son "reificaciones" o cosas porque son primero "objetos". Al contrario, son objetos - en el sentido de despertar la atención de las personas- porque antes son aprehendidos como cosas (Strathern, 1999: 15). La idea de "cosa" es dada por su capacidad de crear relaciones en primera instancia. En este sentido, aunque en el idioma español la separación entre "cosa" y "objeto" no es tan clara como en inglés, lo importante es definir el "objeto estético" como una entidad capaz de construir relaciones como las que se crean entre sujetos. Dice Strathern categóricamente: "Los objetos pueden también ser comprehendidos y aprehendidos como personas" (Strathern, 1999: 15).

Esta personificación puede ser una afirmación un tanto extravagante desde una perspectiva occidental, y pudiera descalificarse fácilmente como meros actos de "fetichismo" o de alienación. Sin embargo, existen ejemplos etnográficos y argumentaciones teóricas en las que los objetos adquieren un poder especial de influencia en la creación de relaciones interpersonales. Aparte de los trabajos antes referidos de Strathern y Gell, es posible encontrar aproximaciones similares en las obras de Arjun Appadurai (1991), Bruno Latour (1993, 2002, 2005), Daniel Miller $(1987,2005)$, Roy Wagner (1986) y en un reciente libro compilatorio de Amiria Henare, Martin Holbraad y Sari Wastell (2007). Appadurai, por ejemplo, propone una antropología de las cosas basada en el valor que las mercancías obtienen dentro de una situación de intercambio que desemboca en la esfera de lo político. Dentro de su propuesta, las cosas se convierten en un aspecto central de la discusión, lo que suscita que ellas mismas se transformen en detonantes de sociabilidad:

Centrándose en las cosas que se intercambian, y no simplemente en las formas o las funciones del intercambio, es posible argüir que lo que crea la conexión entre intercambio y valor es la política, entendida en sentido amplio. Esta afirmación, por desarrollar a lo largo del presente ensayo, justifica la idea de que las mercancías, como las personas, tienen una vida social (Appadurai, 1991: 17).

En el caso de Bruno Latour, la idea de la proliferación de cuasi-objetos, de híbridos que desafían los más arduos intentos de purificación, es algo que no sólo ocurre en contextos llamados "tribales", sino que se extiende al mundo occidental. De ahí que el concepto de "fetichismo", si aún es relevante, debe de ser usado para describir las relaciones complejas entre "cosas" y humanos en un sentido cultural generalizado y no en términos exclusivos para el 
análisis de las sociedades llamadas "primitivas" (Latour, 2002). Desde la perspectiva de Daniel Miller, la reificación de la cultura material redefine de una forma u otra lo que comúnmente se entendía sólo como la instrumentalización del objeto y muestra la complejidad en los actos de apropiación de lo material, particularmente en lo que se refiere al aspecto de su consumo y circulación (Miller, 1987, 2005). En su libro Materiality, Miller interpreta la relación existente entre lo material y lo inmaterial como poseedora de un valor dialógico intrínseco de interdependencia y no de exclusión:

No es sólo que los objetos pueden ser agentes. Las prácticas y sus relaciones crean la apariencia de sujetos y objetos a través de la dialéctica de objetivación, y nosotros necesitamos ser capaces de documentar cómo las personas internalizan y externalizan lo normativo. En suma, necesitamos mostrar cómo las cosas que la gente hace, hacen a la gente (Miller, 2005: 38).

Quizá los casos más cercanos al punto de vista sostenido en este artículo provienen de Henare, Holbraad y Wastell, para quienes el acercamiento al análisis de "las cosas" es más que nada un principio metodológico donde "las cosas encontradas en el trabajo de campo son permitidas de dictar los términos de su propio análisis" (Henare, Holbraad, y Wastell, 2007: 4). En este contexto, los objetos definen cierto tipo de relaciones sociales que el antropólogo tiene que tomar en serio. De esta manera, afirmaciones como "el polvo es poder" y recursivamente "el poder es polvo" - analizadas por Holbraad en el caso etnográfico de los cultos de ifá en Cuba (Henare, Holbraad, y Wastell, 2007: 223265) - ejemplifican la fuerza de las "cosas" en la creación de relaciones en un mundo donde ambos conceptos son indivisibles dentro de un contexto social y forman una sola entidad en su percepción material. De modo similar en el caso de Wagner, la idea de símbolos que se instituyen por ellos mismos es una forma de decir que los objetos y su significado están estrechamente relacionados y se constituyen como una fuerza indisoluble que impide cualquier separación arbitraria entre significado y significante (Wagner, 1986: 14-33), y que impone un amalgamiento entre concepto y percepción.

Esta identificación entre concepto y percepción de la que habla Wagner, desde mi punto de vista, activa la apreciación estética del objeto material. Aunque la manera en que se asimila esta experiencia varía de cultura a cultura y de sujeto a sujeto, es posible entrever que detrás de la personificación de los objetos se encuentra una relación todavía más estrecha entre los conceptos de cultura y acción. Para hacer más clara esta formulación teórica, me gustaría mostrar cómo la personificación de "cosas" opera etnográficamente en el contexto ritual de la capoeira angola en Brasil, donde he realizado trabajo de investigación durante los últimos diez años.

\section{EL BERIMBAU: LA PERSONIFICACIÓN ESTÉTICA DE UN OBJETO MUSICAL EN LA CAPOEIRA ANGOLA}

La capoeira es un arte marcial de raíz afrobrasileña que combina aspectos de lucha, danza y juego. Sus orígenes son un tanto inciertos. Investigaciones históricas la sitúan como una práctica que se desarrolla en la primera mitad del siglo xIx (Soares, 2001). Sin embargo, es posible que se remonte a épocas más antiguas del periodo colonial en Brasil, quizá al inicio del siglo XvII, con la introducción de la esclavitud en el territorio (Assunção, 2005). Actualmente la capoeira está dividida en tres estilos: la capoeira angola, la regional y la contemporánea. El estilo angola se define por sus practicantes como el más tradicional y apegado a sus raíces africanas. Las otras dos formas de capoeira se asemejan por su énfasis en el aspecto marcial combativo, la proclividad a incorporar nuevos elementos técnicos en su práctica, así como por la diversidad de subestilos, reglas para dar grados y reconocimientos a la destreza física y espiritual —en eventos públicos llamados comúnmente "batizados", bautizos-. 
Aunque esta diferenciación de estilos es muy esquemática y requeriría mayor profundización, es importante mencionar que es producto de una historia común y de perspectivas discrepantes sobre la práctica y los usos de la capoeira en Brasil.

No obstante, si algo distingue a la capoeira angola de los otros dos estilos es su énfasis en la música. Esto no significa que la música sea irrelevante para la capoeira regional y la contemporánea, ya que existe en sus performances y es parte de las habilidades que aprende un jugador. Sin embargo, la forma de tocar y el rango de variaciones y experimentaciones musicales que pueden existir en los grupos de regional o contemporánea es mayor al que existe en la capoeira angola. De hecho, el ámbito de variaciones musicales de esta última es muy limitado y restringido, lo que definitivamente tiene repercusiones en la forma en que los practicantes interactúan y asimilan la música. Como ha advertido Greg Downey:

Los ritmos instrumentales afectan el desarrollo de un juego, controlan la severidad de la competición, y disponen el estilo de interacción... La música instrumental, a diferencia del canto, influencia el juego constantemente, interactúa a cada momento con la forma en que se mueven los jugadores (Downey, 2005: 87).

Por este motivo, en Salvador y en otras ciudades de Brasil (véase imagen 1) la enseñanza de la música es un factor imprescindible. No hay academia en la que no se impartan clases de música de capoeira y donde los practicantes no experimenten un doble proceso de aprendizaje como jugadores y músicos al mismo tiempo. Dicho aprendizaje se basa principalmente en el dominio del instrumento musical llamado berimbau ${ }^{1}$ (véase imagen 1). El berimbau es un instrumento musical de resonancia, formado por una vara de 1.5 metros de largo, un cable de

\footnotetext{
${ }^{1}$ El nombre de berimbau proviene del árbol llamado beriba, del cual se extrae la materia prima para construir el instrumento.
}

acero - arame - , una calabaza hueca - cabaça- y una sonaja - caxixi-. Se asemeja a un arco y su sonido es producido por la tensión que ejerce el cable de acero con la vara de madera y la calabaza que se ajusta en la base como caja de resonancia. El sonido de un berimbau tensado es hueco y en general fuerte y agudo. Su intensidad depende del tipo de calabaza que se utilice y de la vara que se escoja. En los performances de angola normalmente se cuenta con la presencia de tres berimbaus - gunga, medio y viola-, que forman el núcleo de la orquesta musical (véase imagen 1).

Los otros instrumentos de la orquestra musical son dos panderos que se colocan normalmente al lado del berimbau gunga y del berimbau viola respectivamente; una doble campana que se llama agogó, que se sitúa al lado de uno de los panderos; un güiro llamado reco-reco, y finalmente un tambor largo similar a una conga llamado atabaque (véase imagen 2). En los performances estos instrumentos sirven como marcadores del ritmo de la capoeira y se caracterizan por tener variaciones mínimas. En este sentido, los berimbaus son los únicos encargados de hacer variaciones y de acelerar o pausar la música.

La importancia del berimbau como símbolo de la capoeira es un fenómeno relativamente reciente que probablemente ocurrió con el proceso de institucionalización de los estilos en academias, aunque no se descarta la posibilidad de que el berimbau ya existiera y fuera usado en la capoeira en un periodo anterior al siglo xx. Los orígenes del berimbau son inciertos y su desarrollo histórico no es claro. De acuerdo con algunos estudios históricos, el berimbau en Salvador no aparece en registros documentales, periodísticos o pictóricos sino hasta la década de 1930. Parece que no hay evidencia clara de su uso constante dentro de la capoeira antes de eso (Abreu, 1999; Assunção, 2005; Dias, 2006; Oliveira, 2005). De forma similar, en Río de Janeiro, donde existe más información sobre la historia de la capoeira durante el siglo XIX, no hay testimonios sobre este instrumento musical (Soares, 2001). 


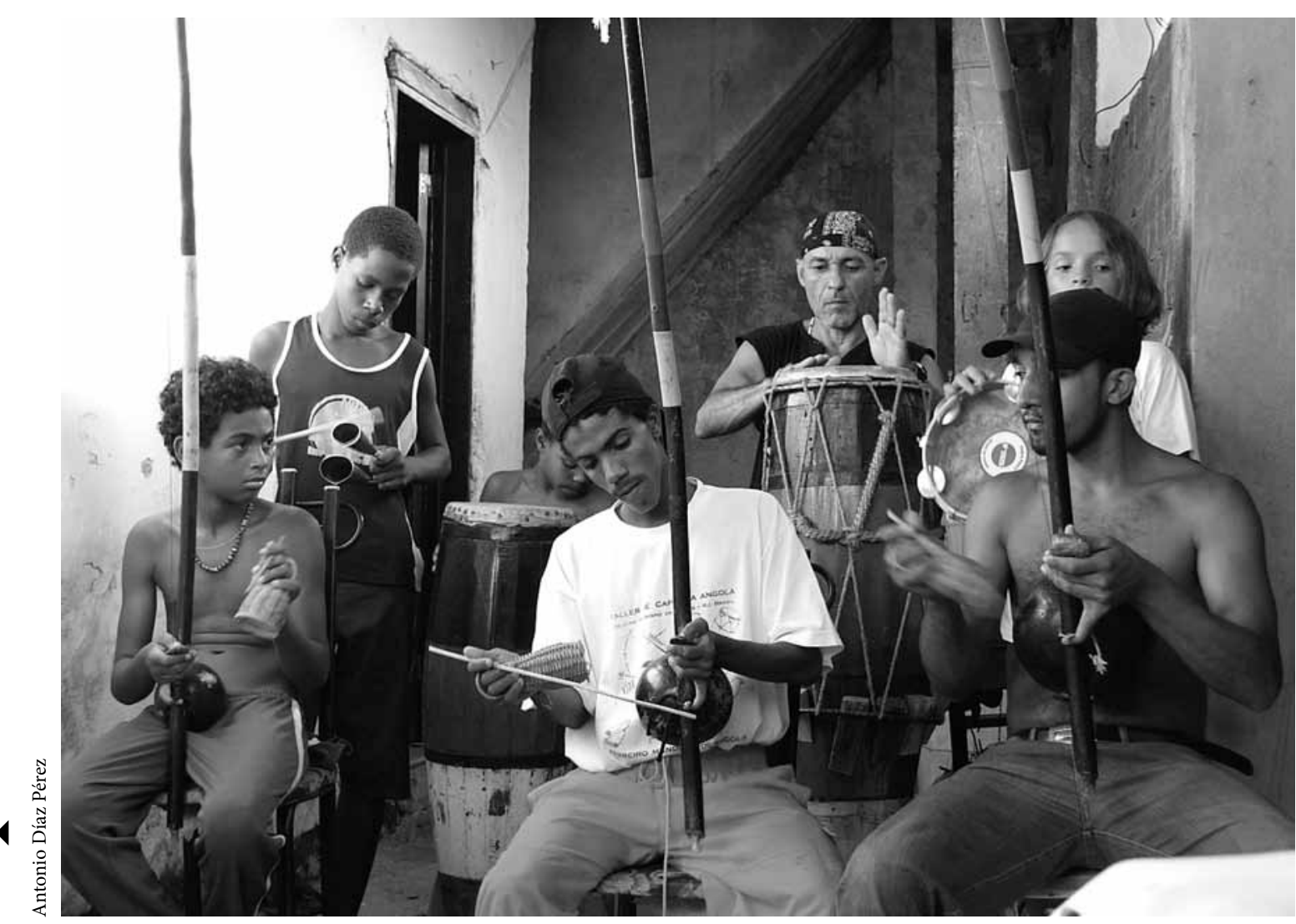

Imagen 1. Contramestre Rogerio, extrema derecha, del grupo Terreiro Mandinga de Angola enseña a tocar el berimbau a dos estudiantes en el patio de su casa en Jardim Gramacho, Duque de Caxías, Río de Janeiro, Brasil, 2005.

No se sabe a ciencia cierta cómo surgió la relación entre el berimbau y la capoeira y esto parece formar parte de la propia mitología del berimbau. Algunos maestros - mestres - de capoeira afirman que este instrumento no tenía un objetivo musical en su origen. Por el contrario, era utilizado como una especie de campana por los recolectores de basura para llamar la atención de las personas en los barrios del centro de la ciudad. Desde su perspectiva, la capoeira se desarrolla como un fenómeno urbano practicado principalmente en las calles por individuos asociados al crimen, el desorden, las mafias y la vagancia. Este sector de la sociedad, junto a otro grupo de practicantes que incluye a trabajadores portuarios, policías, soldados, marineros y cargadores, serán los responsables de la introducción del berimbau en las rodas - lugares donde se juega capoeira- como un elemento adicional a la música que se tocaba en los encuentros entre jugadores (Dias, 2006).

Frederico de Abreu, uno de los especialistas en el tema, relata en una entrevista que los practicantes de la capoeira de inicios del siglo xx usaban primeramente tambores - atabaques - de manera similar a como lo hacían los devotos de la religión afrobrasileña del Candomblé. Afirma que muchos de los jugadores de capoeira vieron al berimbau como un elemento que podía suplantar el uso de los tambores en la música, y así, de forma casi espontánea, se produjo la transición de los instrumentos. A partir de la década de 1940, el berimbau se convierte en un símbolo del carácter africano de todos los estilos de capoeira. Varios maestros aseguran que es un 
instrumento africano que establece una conexión suprema con los antepasados de esta arte marcial. La africanidad del berimbau ha sido un tema que ha generado discusiones entre expertos y practicantes. Muchos mestres han viajado a Angola, a la costa de Benín y Nigeria con el único objeto de rastrear los orígenes del berimbau. Independientemente de lo que pueda decirse acerca de este tipo de esfuerzos, es innegable que hay instrumentos muy parecidos o casi iguales al berimbau en varios lugares de la costa occidental del continente africano (Shaffer, 1977). No puedo decir con certeza cuál es el significado y uso de estos instrumentos en África. De acuerdo con el etnomusicólogo Richard Graham, los orígenes del berimbau están fuertemente asociados con las tribus hungu de Luanda y mbulumbumba en el sudoeste de Angola (Greham, 1991: 2).

Sea esto verdad o una más de las narrativas míticas sobre el origen de la capoeira, lo importante es destacar que en muchas de las actuales academias de esta arte marcial, de estilo angola por lo menos, el berimbau ha tomado un lugar central tanto en la música como en los performances (véase imagen 3 ). Esto ha resultado en una creciente especialización sobre las posibilidades musicales del instrumento y la emergencia de una complejidad de tonos y combinaciones de los tres tipos de berimbau implicados en la orquesta. En la actualidad, aprender a tocar el berimbau forma parte de la rutina diaria de enseñanza en una academia del estilo angola tanto en Brasil como en el extranjero, al grado de que los mestres consideran que un capoeirista que no sabe tocar un berimbau es un capoeirista "cojo" - capen$g a-$, un jugador falso e incompleto (Downey, 2005: 88).

El carácter casi sagrado del berimbau lo convierte en un objeto que asume caracteres de sujeto dentro del mundo de la capoeira. Una de las maneras más frecuentes de esta transformación es la elaboración del propio instrumento. Aunque hoy en día la mayoría de las academias compran en los mercados las varas sin curar o no participan en todo el proceso de creación del instrumento, según mestre Decanio, uno de los teóricos de la capoeira más reconocidos, hace algunos años era posible ver a jugadores de capoeira entrar en la parte semiselvática del estado de Bahía y cortar las beribas para sus grupos. A decir de Decanio, actualmente todas las varas se compran con intermediarios, si bien la tradición de fabricar el propio instrumento musical pervive en algunos grupos. Por ejemplo, en la Academia Grupo Zimba, donde hice trabajo de campo, su líder mestre Boca do Rio (véase imagen 2) ponía un marcado énfasis en la relación que se establecía entre el practicante y el berimbau que estaba fabricando. Podía pasar horas mostrando con sutileza el proceso, paso por paso, para construir un buen instrumento. ${ }^{2}$ Para él, la fabricación personal de un berimbau creaba un vínculo emocional e indisociable entre el sujeto y el instrumento, similar al que se instaura fraternalmente entre personas. El berimbau era considerado un amigo, un confidente y un protector.

Un buen berimbau puede durar entre dos y diez años por lo menos. Un jugador pasa mucho tiempo con él, lo que produce un lazo emotivo que valora como parte de su tradición de capoeirista. En algunos casos, el instrumento musical se transforma en una extensión del propio jugador, en un maestro más. Es durante la dinámica del juego cuando el berimbau se convierte verdaderamente en un sujeto. Sería difícil dar una descripción detallada de todas las reglas que conforman la lógica de interacción de la capoeira angola, pero quisiera citar aquellas que se refieren explícitamente al berimbau y cómo influyen en su personificación.

La capoeira es concebida por sus practicantes como un juego, el cual se desarrolla en un círculo de combate llamado "roda". La roda es un espacio físico no mayor a un ring de boxeo, donde los practicantes - encargados de delimitar el círculo con sus

\footnotetext{
${ }^{2}$ Consistía en limpiar la vara con una lija y un pedazo de vidrio, hacer los cortes exactos a las calabazas, extraer el alambre de una vieja llanta de automóvil y finalmente añadir los ungüentos necesarios a la beriba para hacerla resistente y flexible en cuestión de días.
} 


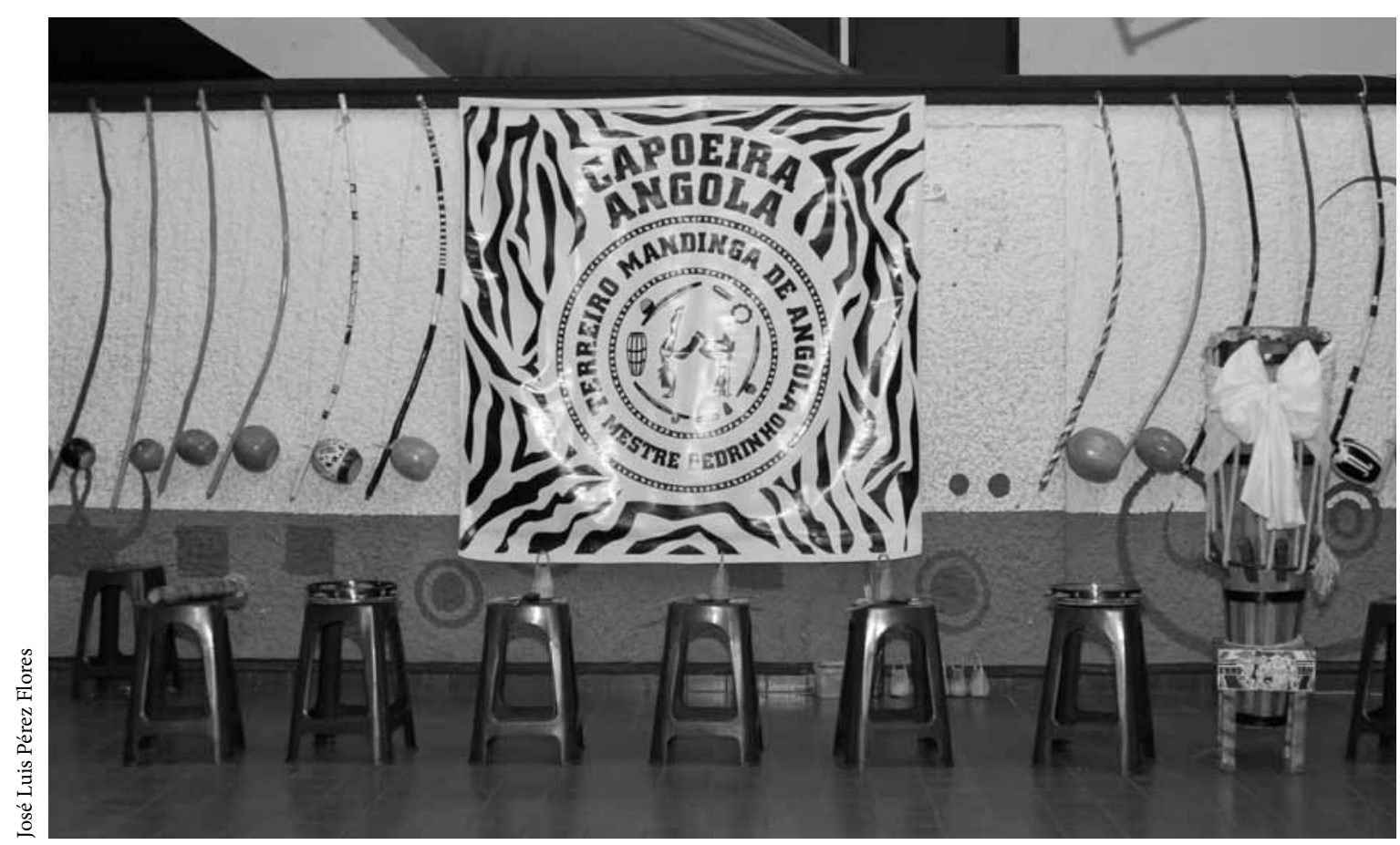

Imagen 2. Batería musical de la capoeira con berimbaus adornando las paredes de la academia del grupo Terreiro Mandinga de Angola durante el Día de la Conciencia Negra, 2011.

cuerpos- actúan en tres modalidades simultáneas: ejecutantes, músicos y audiencia. El juego involucra a dos personas que se enfrentan cara a cara dentro de la roda (véase imagen 4). La lógica de interacción consiste en evadir al oponente y simular actos de violencia por medio de engaños corporales (Downey, 2005; Lewis, 1992). El objetivo del juego es abrir el cuerpo del adversario y mostrar sus puntos vulnerables, al tiempo que se procura mantener el propio cuerpo cerrado y lejos de todo contacto. El cuerpo de un jugador se abre con movimientos acrobáticos que disfrazan las intenciones reales de ataque. En teoría, no hay ganadores ni perdedores en el juego de angola, aunque en muchos casos es fácil percibir quién tiene más control y habilidad dentro de la roda. Las reglas implícitas del juego son de cierta manera flexibles, pero se privilegian arrastres — rasteiras - y cabezadas — cabeçadas - como ataques para abrir y derribar a un adversario.
Un juego puede durar de dos a diez minutos, según el nivel de los jugadores y el número de personas que se encuentren en la roda. No existe roda sin música en vivo. La música crea la atmósfera de danza del juego por medio de canciones cantadas al unísono por todos los participantes, esto le da un aura sagrada y ritual a la capoeira. De forma más activa, la música sirve como un comentario de las acciones que acontecen en la roda y guía los movimientos en la intimidad del contacto físico de los jugadores. En este contexto los berimbaus han adquirido un valor especial. Se dice que los tres berimbaus que forman la parte medular de la orquesta mantienen un diálogo constante con los jugadores y entre ellos mismos. Los berimbaus, puntualiza mestre Valmir — uno de mis informantes-, "hablan, te llaman y se llaman entre ellos". Son responsables del nivel de intensidad del juego por medio de sus "voces", las cuales se producen con tonos huecos y fuertes. 
Estas voces crean una especie de mantra, un ritmo repetitivo y estable que fluctúa entre melodía y estridencia. La melodía se forma al combinar tonos asimétricos entre los tres berimbaus. De esta manera, el berimbau gunga es la voz principal, que mantiene la velocidad y el ritmo de toda la orquesta. Sigue el berimbau medio, que ejecuta una voz igual en melodía, pero de manera invertida al gunga. Finalmente sigue el berimbau viola, el más agudo y difícil de tocar para cualquier jugador, y cuya función es improvisar y guiar las acciones del juego a un nivel muchas veces impredecible. El viola entra a contratiempo de los otros berimbaus y manda la disonancia directamente a los oídos del jugador y de la audiencia sin causar pérdida de armonía musical.

Aquí habría que establecer la diferencia entre lo que Greg Downey ha llamado "la materialidad de la música" (Downey, 2002) y lo que defino como la personificación del propio objeto. Si bien los sonidos del berimbau son percibidos e incorporados por los jugadores, el hecho de que se les denomine "voces" habla de una transformación ontológica de lo que es un berimbau. En este cambio de énfasis puede vislumbrarse que lo musical es el primer momento de una trascendencia más importante y sustancial que ocurre cuando la propia música se convierte en un lenguaje que emana de un nuevo sujeto, afectando la dinámica de interacción.

Por tanto, las vibraciones de los berimbaus, sus "voces", proveen a los jugadores experimentados indicaciones, mensajes para ser escuchados y seguidos. En este sentido se dice que los berimbaus hablan y dan avisos acerca de vulnerabilidades y peligros en el juego. De cierto modo se convierten en símbolos dominantes, parafraseando a Victor Turner (1968), ellos dirigen las acciones y desarrollan una trama a seguir. La relación entre la acústica de los berimbaus y los cuerpos de los jugadores es un tema que requiere mayor profundización y minuciosidad etnográfica. Por lo que he llegado a percibir, la experiencia acústica provocada por los berimbaus activa el movimiento de los cuerpos.

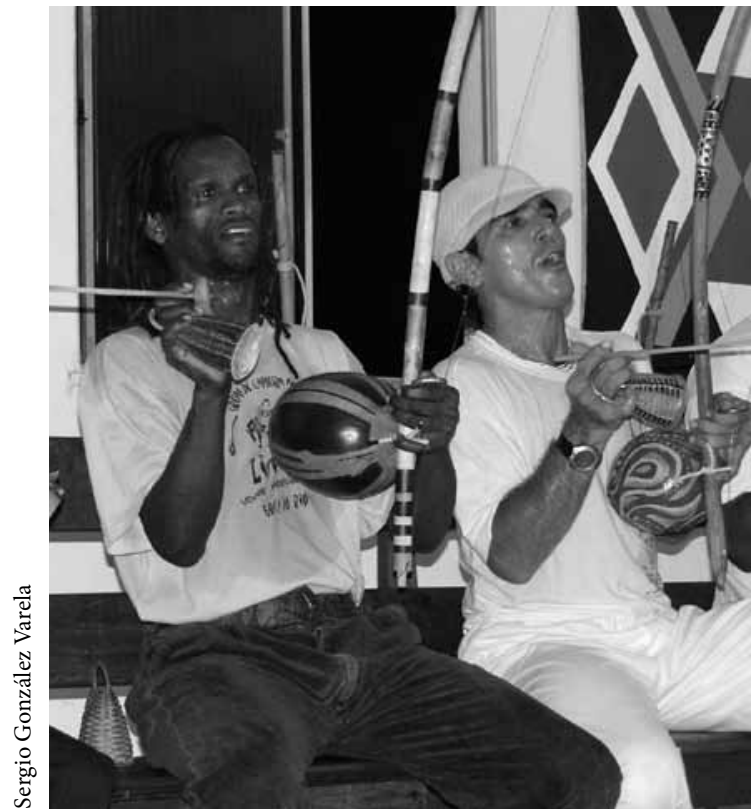

Imagen 3. Mestres Boca do Rio y Poloca tocando en la academia de Grupo Nzinga en Salvador, Bahía, Brasil, 2006.

Los jugadores experimentados aseguran que la disonancia producida por el berimbau viola manda mensajes codificados que les informan cuándo y hacia dónde moverse para evitar ataques y sorpresas en el juego. Esto evidencia el carácter "personal" de sujeto que se le atribuye al berimbau. Al enviar mensajes y hablar, un simple instrumento musical se transforma en un agente, en algo más que un objeto material, se convierte en un jugador más en la roda.

Un último aspecto que ejemplifica el carácter personal del berimbau es su capacidad de mandar señales de advertencia a los jugadores. De acuerdo con lo que varios mestres comentaron, una roda siempre está llena de buenas y malas energías que un jugador puede atraer o llevar hacia otras personas. De ahí el énfasis por mantener un cuerpo cerrado antes de un performance y el cuidado minucioso de ciertas reglas y restricciones. No obstante estos cuidados, siempre hay momentos en que los jugadores no pueden controlar y a menudo acontecen circunstancias no previstas. Algunos mestres aseguran que pueden ser objeto de actos mágicos perpetrados por 
otros mestres en la roda, como rachas de mala suerte, embrujos o pérdida de energía física y espiritual. Para contrarrestar estos actos, los jugadores se valen de las "voces" de los berimbaus y de las señales que mandan. En particular, se asume que un berimbau puede absorber la energía negativa en una roda. Cuando esto sucede, el alambre del instrumento musical que sostiene la calabaza se quiebra por razones que nadie puede explicar. Este acto, en la mayoría de los casos, suscita la interrupción del juego y la búsqueda de los "culpables" de llevar la energía negativa a la roda. El juego no reinicia sino hasta que el alambre es sustituido u otro berimbau es solicitado, y los llamados culpables son señalados y advertidos de manera lúdica sobre la importancia de no traer energía negativa a una roda. Se cree que esta situación de ruptura del alambre es una forma más de "hablar" del berimbau y pone de manifiesto su capacidad de transformarse en un sujeto de acción.

\section{CONCLUSIÓN: RELACIONES INQUEBRANTABLESY EL ESTATUTO ONTOLÓGICO DE LOS OBJETOS ESTÉTICOS}

El ejemplo etnográfico sobre el berimbau en el juego de capoeira angola muestra la complejidad que existe en la relación entre lo material y la acción humana. No es posible, por el momento, aventurar un argumento definitivo sobre los elementos involu-crados en la construcción de esta relación. Por un lado, nos enfrentamos a un objeto que, dada su

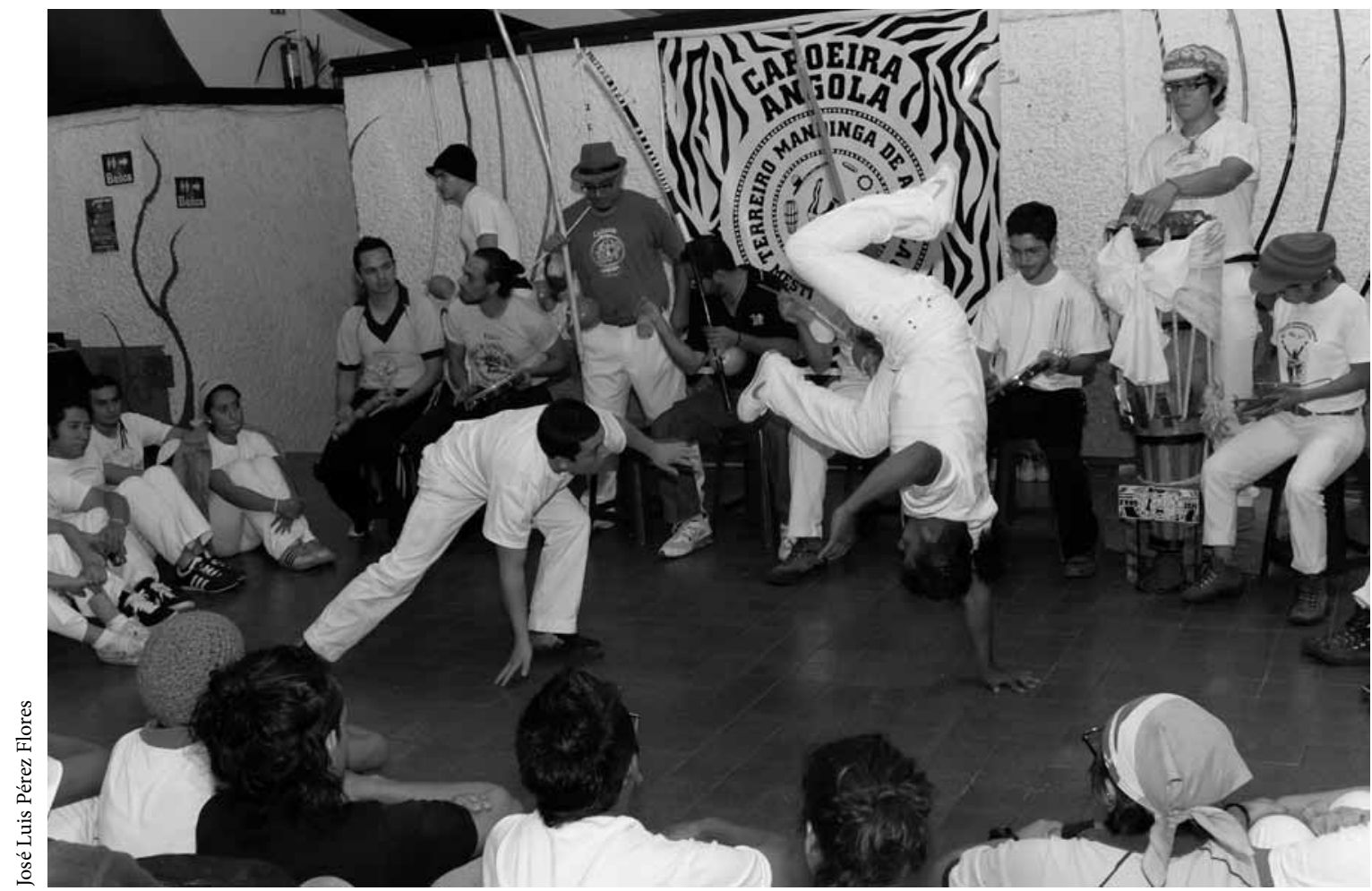

Imagen 4. Jugadores de capoeira en la roda del grupo Terreiro Mandinga de Angola durante la celebración del Día de la Conciencia Negra en la ciudad de México, 2011. 
especificidad musical, tiene un efecto claro en los cuerpos de los participantes. Los cuerpos se mueven al compás de la música y los sonidos se convierten en voces, en guías. Ante el hecho, ¿es posible expandir este tipo de fenómeno a otros contextos culturales? De qué manera la transformación de un objeto en sujeto activo descubre las múltiples aprehensiones que la gente asume acerca de su mundo. Quizá en ámbitos relacionados con el ritual, la religión, el arte y el consumo sea dable encontrar fenómenos de personificación similares. Lo cierto es que este tipo de personificación nos obliga a replantear el estatuto ontológico de los llamados "objetos" o "cosas" y a redefinir el papel de la estética en esta transformación. Lo que el caso del berimbau ejemplifica es que el valor del objeto en su sentido casi existencial y su percepción dependen de una relación que es la condición misma del objeto. Esta relación es posiblemente el fundamento de la reevaluación ontológica de lo material. La arquitectura de sentido inmanente del objeto depende de este factor extrínseco e indisoluble dado por la condición de relación potencial del sujeto. No hay forma de aislar su sentido y su función de las relaciones que se establecen entre humanos, pero hay una intensidad del objeto que diluye sus propiedades materiales como condición de existencia, de esta manera define una nueva forma de relación estética y de aproximación perceptual en su nueva calidad de sujeto.

La reevaluación del estatuto ontológico del objeto material implica un alejamiento de soluciones sociocéntricas que en muchas ocasiones obvian la existencia a priori de lo concreto. Lo material y sus efectos requieren dilucidación. Los objetos no son meros agentes funcionales reducidos al uso que las personas les den. Al contrario, los llamados “objetos", sobre todo aquellos que suscitan una mirada estética, como el berimbau en la capoeira, se transforman en agentes que en algunos casos requieren ser tratados seriamente como personas y como sujetos proveídos de la capacidad de influir en las decisiones y acciones humanas. Por increíble que parezca, aunque esto es un problema causado por nuestra propia perplejidad frente a la diversidad cultural, la personificación de los objetos es un hecho innegable que demanda un reconocimiento serio y responsable en sus propios términos y con base en las relaciones que crea, afecta y transforma.

\section{Referencias}

Abreu, Frederico de, 1999, A capoeira bahiana no século XIX, Instituto Jair Moura, Brasil.

Appadurai, Arjun (ed.), 1991, La vida social de las cosas. Perspectiva cultural de las mercancías, Grijalbo, Consejo Nacional para la Cultura y las Artes, México.

Assunção, Mathias R., 2005, Capoeira. The History of an Afro-Brazilian Martial Art, Routledge, Nueva York y Londres.

Barthes, Roland, 1985, Crítica y verdad, Siglo XXI, México. , 1999, Mitologías, Siglo XXI, México.

Baudrillard, Jean, 1997, El sistema de los objetos, Siglo XXI, México.

Dias, Adriana Albert, 2006, Mandinga, manha e malicia, uma historia sobre os capoeiras na capital da Bahia (1910-1925), Editora da Universidade Federal da

Downey, Greg, 2002, "Listening to Capoeira: Phenomenology, Embodiment, and the Materiality of Music", en Ethnomusicology, vol. 46, núm. 3, pp. 487-509.

— 2005, Learning Capoeira: Lessons in Cunning from an Afro-Brazilian Art, Oxford University Press, Oxford.

Gell, Alfred, 1998, Art and Agency. An Anthropological Theory, Clarendon Press, Oxford.

Graham, Richard, 1991, "Technology and Culture Change: The Development of the 'Berimbau' in Colonial Brazil", en Latin American Music Review, vol. 12, núm. 1, pp. 1-20.

Greimas, Algirdas, 1983, La semiótica del texto. Ejercicios prácticos: análisis de un cuento de Maupassant, Paidós, Barcelona.

, 1997, De la imperfección, Benemérita Universidad Autónoma de Puebla, Fondo de Cultura Económica, México.

- y Joseph Courtès, 1991, Semiótica. Diccionario razonado de la teoría del lenguaje, Gredos, Madrid. y Jacques Fontanille, 1994, Semiótica de las pasiones, Siglo XXI, México. 
, 1995-1996, “El bello gesto”, en Morphé. Ciencias del Lenguaje, núms. 13-14, Benemérita Universidad Autónoma de Puebla, pp. 29-47.

Henare, Amiria, Martin Holbraad y Sari Wastell (eds.), 2007, Thinking through Things: Theorising Artefacts Ethnographically, Routledge, Londres.

Latour, Bruno, 1993, We Have Never Been Modern, Harvard University Press, Cambridge, Massachusetts.

- 2002, Reflexão sobre o culto moderno dos deuses fe(i)tiches, Bauru, Editora da Universidade do Sagrado Coracão, São Paulo.

- 2005, Reassembling the Social: An Introduction to Actor-Network-Theory, Oxford University Press, Oxford.

Lewis, Lowell, 1992, Ring of Liberation; Deceptive Discourse in Brazilian Capoeira, The University of Chicago Press, Chicago y Londres.

Miller, Daniel, 1987, Material Culture and Mass Consumption, Blackwell, Oxford.

(ed.), 2005, Materiality, Duke University Press, Durham.
Oliveira Pires de, Josivaldo, 2005, No tempo dos valentes, os capoeiras na cidade da Bahia, Quarteto Editora, Bahía.

Ricoeur, Paul, 2000, "Narratividad, fenomenología y hermenéutica”, en Anàlisi, núm. 25, pp. 189-207.

Saussure, Ferdinand de, 1996, Curso de lingüística general, Fontamara, México.

Shaffer, Kay, 1977, O berimbau-de-barriga e seus toques, Instituto Nacional do Folclore, Funarte, Río de Janeiro.

Soares, Eugenio, 2001, A capoeira escrava e outras tradições rebeldes no Rio de Janeiro. 1808-1850, Editora da Unicamp, Campinas.

Strathern, Marilyn, 1999, Property, Substance, and Effect: Anthropological Essays on Persons and Things, The Athlone Press, Londres.

Turner, Victor, 1968, The Forest of Symbols, Aspects of Ndembu Ritual, Cornell University Press, Londres.

Wagner, Roy, 1986, Symbols that Stand for Themselves, University of Chicago Press, Chicago. 